\title{
Protesta Social en Chile, 2019-2020: fracaso de un modelo económico
}

\section{Social protest in Chile, 2019-2020: failure of an economic model}

DOI: https://doi.org/10.29166/tyc.v1i20.2094

\begin{abstract}
Álvaro Cuadra
Ensayista y académico chileno. Licenciado en Letras y Magister en Literatura de la Pontificia Universidad Católica de Chile. Doctor de la Sorbonne (París, Francia) en Semiología y Letras. Su trabajo teórico se orienta hacia el pensamiento crítico en torno a las comunicaciones y la cultura actual. Entre sus obras publicadas destacan: De la Ciudad letrada a la Ciudad virtual (2003), Hiperindustria cultural (2008), Ópticas de la modernidad (2013), Comunicación política y democracia en América latina (2016), El Príncipe posmoderno (2019). Se desempeña como docente e investigador en la Facultad de Comunicación Social de la Universidad Central del Ecuador.
\end{abstract}

Correo: arcuadra@uce.edu.ec

\section{Resumen}

En este artículo de reflexión hemos querido dar una mirada panorámica sobre las singularidades de la protesta social en Chile 20192020. Para ello, hemos utilizado tres encuestas recientes muy reconocidas en el ámbito chileno -CEP, MORI, CADEM- para intentar desentrañar las causas mediatas e inmediatas del estallido social.

Palabras clave: modelo chileno, redes sociales, protesta.

\section{Abstract}

In this reflection article we wanted to give a panoramic look at the features of the social protest in Chile 2019-2020. To do this, we have used three recent well-known surveys in Chile - CEP, MORI, CADEM - to try to unravel the immediate and mediate causes of the social outbreak.

Keywords: chilean model, social networks, protest. 
Il faut redonner à ce mot / démocratie/sa puissance de scandale. Il a d'abord été une insulte: le gouvernement de la canaille, de la multitude, de ceux qui n'ont pas de titre à gouverner ${ }^{1}$.

Jacques Rancière Citado por Bernard Stiegler

\section{Antecedente: protesta estudiantil 2011}

Se ha sostenido que en el Chile actual estaríamos ante una revolución del siglo XXI, una forma inédita que no posee una vanguardia, ni líderes ni portavoces, en fin, se trataría de una revolución de "final abierto" (Karmy, 2019) En efecto, el pueblo chileno quiere dejar atrás el pacto oligárquico encarnado en la Constitución de 1980, concebida bajo la tutela de la dictadura militar encabezada por Augusto Pinochet. Como señala con lucidez el sociólogo Mauro Salazar: "Y ya lo sabemos: aquí ha irrumpido un movimiento sin partidos, sin vertebración, sin texto para administrar el presente, pero con una prosa que ha venido a derogar la letra institucional del orden Pinochetista" (Salazar, 2019)

Con todo lo inusitado de la actual protesta social chilena, debemos reconocer que sí existe un hecho histórico que, guardando las distancias y precauciones, bien pudiera considerarse un antecedente de lo que acontece actualmente. Nos referimos, por cierto, a las protestas estudiantiles del año 2011. El protagonismo juvenil se ha hecho evidente en ambos eventos históricos: los mismos jóvenes cautivos de la marginalidad, la precariedad y el endeudamiento.

En una primera aproximación, ya advertíamos una serie de singularidades de dicha revuelta de los estudiantes que podríamos resumir en los siguientes términos: "Nos llamaba la atención el carácter "estético-performativo" de las manifestaciones, donde los gritos por una educación pública gratuita se conjugaban con "acciones de arte", cuerpos desnudos y muchas otras formas expresivas que le otorgaban un clima carnavalesco a la marcha" (Cuadra, 2019)

A esto habría que agregar otras características que parecieran hacerse presente en la protesta social 2019: "Los estudiantes no solo se expresaban de manera desenfadada y lúdica, sino que además se organizaban en verdaderas "asambleas permanentes" cuyo talante igualitario y participativo resultaba evidente. Es cierto que algunos de sus dirigentes emblemáticos poseían una definida filiación política, sin embargo, el movimiento se mostraba reacio a una proximidad hacia los partidos políticos tradicionales" (Cuadra 2019)

Este distanciamiento que se hizo evidente entre el movimiento social estudiantil y los partidos políticos, especialmente de la izquierda, exhibía un hiato que no haría sino profundizarse y radicalizarse en la actualidad, y que ya nos planteaba interrogantes de fondo: "El movimiento estudiantil chileno resulta ser un fenómeno del más alto interés en cuanto nos obliga a plantear algunas interrogantes nada fáciles de responder. Por de pronto, y contra toda una tradición partidista, los estudian-

1 Es necesario restituir a la palabra "democracia" todo su poder de escándalo. Al principio era un insulto: el gobierno de la canalla, de la multitud, de aquellos que no poseen el título para gobernar. Traducción del autor. 
tes construyen asambleas de cuño libertario, ajenas a los partidos de la izquierda más tradicional. Cabe preguntarse qué nuevos modos de pensar y sentir están orientando este hacer. Lo que nos lleva a una cuestión no menor: qué mediaciones hacen posible las nuevas escenas de disenso" (Cuadra 2019).

\section{Protesta social: percepción de los chilenos}

Chile ha dejado de ser ese idílico "oasis" que soñaba hasta ayer una derecha soberbia. La realidad de Chile no es muy diferente a la del resto de Latinoamérica, caracterizada por la desigualdad, la violencia y la corrupción. No nos engañemos, Chile todavía no ha salido del ciclo liberal-autoritario inaugurado por un cruento golpe de estado en 1973 y consolidado en la Constitución de 1980. Basta examinar el primer gabinete del actual gobierno para reconocer, de inmediato, los rostros de "Chacarillas", los rostros de los hijos de la dictadura. Una economía neoliberal voraz ha generado uno de los países más desiguales del mundo. Al mismo tiempo, la actual mascarada democrática no puede disimular, después de treinta años, ni sus arrugas ni su marcada herencia pinochetista.

Una envejecida clase política, así autoproclamada "progresista”, que lleva más de tres décadas al amparo de lo que fue la Concertación y entregada al poder burocrático-militar del Estado, se muestra impotente frente a las demandas populares que adquieren una fisonomía rizomática. La protesta social con toda su carga de ira y violencia, no posee todavía ni un liderazgo ni un contenido político claro, esto torna el destino inmediato de esta protesta en algo muy incierto. Esta carencia de li- derazgo visible se explica, en parte, porque la violencia diseminada en la sociedad responde más bien a una lógica reticular y descentralizada, al igual que las RSO (Redes Sociales on line), y a pulsiones que se relacionan más con el consumo que con las militancias o ideologías políticas.

Como una manera de aproximarnos a la percepción que tienen los chilenos del estallido social, utilizaremos los datos recogidos por tres encuestas realizadas entre diciembre de 2019 y enero de 2020.

La primera encuesta, "Barómetro del Trabajo", indaga sobre el plebiscito del próximo 26 de abril y sobre cuestiones de carácter económico; fue realizada por MORI / FIEL entre el 06 y el 15 de enero 2020, con un tamaño muestral de 1000 casos y una representación de toda la población adulta de Chile con un error del 3\%. La segunda encuesta que nos interesa es el "Estudio Nacional de Opinión Pública No 84", efectuada por CEP en diciembre 2019. Esta encuesta fue realizada entre el 28 de noviembre 2019 y el o6 de enero 2020 sobre una muestra estratificada, aleatoria y probabilística de 1496 personas entrevistadas en sus hogares en 117 comunas del país. El error muestral se estima en un 3\%, considerando varianza máxima y un 95\% de confianza. Por último, utilizaremos algunos datos de la encuesta Plaza Pública. Estudio No 317, primera semana de febrero 2020/ CADEM. En este caso se trata de una encuesta telefónica aplicada a 709 casos, según el sistema Cati, mediante un muestreo probabilístico y aleatorio, con un margen de error de $3.7 \%$ y $95 \%$ de confianza.

Lo primero que podemos constatar es un profundo apoyo a la democracia de parte de la población: el $68 \%$ apoya la democracia, frente a un $16 \%$ que apoya formas autoritarias de gobierno y un $14 \%$ que es indiferente. 
Ahora bien, al ser interpelados por el nivel de satisfacción con la democracia, el $83 \%$ se declara no satisfecho y solo un $15 \%$ se declara satisfecho. Restando el $15 \%$ de satisfechos al $68 \%$ que apoya la democracia, nos queda un $43 \%$ de "Demócratas Insatisfechos", lo cual nos lleva a una conclusión preliminar: Hay una clara demanda de más y mejor democracia. (Mori, 2020) (Véase Cuadro $\mathrm{N}^{0} 1$ ) Esto se hace más claro cuando examinamos el ítem de la igualdad ante la ley: el 90\% de los chilenos cree no hay igualdad ante la ley. Cuando se pregunta para quién se gobierna, la respuesta es rotunda, un $83 \%$ responde "Grupos poderosos en su propio beneficio"

Como una estrategia meramente didáctica, intentaremos describir muy sucintamente, desde nuestra perspectiva, los puntos que nos parecen clave del estallido social en Chile en tres niveles, a saber: lo económico, lo político y lo socio-cultural.

\section{Cuadro No. 1}

\section{Satisfacción con la democracia}

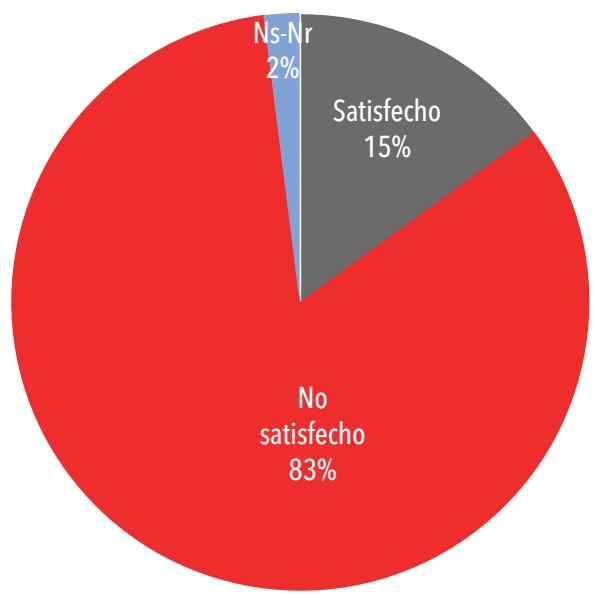

*En general, ¿Diría usted que está muy satisfecho, más bien satisfecho, no muy satisfecho o nada satisfecho con el funcionamiento de la democracia en Chile?

Fuente: isARÓMETR@

\section{Crisis tecno-económica}

3.1. Insatisfacción económica. El llamado "modelo chileno" se exportó a Latinoamérica como el más exitoso de la región. Hoy se derrumba estrepitosamente, pues ha demostrado que acrecienta la desigualdad. No puede haber una macroeconomía sana si no hay una microeconomía que satisfaga las necesidades de las mayorías. El sueldo mínimo de un trabajador no supera los 420 dólares.

Un punto que nos parece muy importante es reconocer que la protesta encuentra uno de sus fundamentos en el evidente de que "los chilenos no llegan a fin de mes" con sus magros ingresos, (Véase Cuadro $\mathrm{N}^{\circ}$ 2) Esto, que pudiera parecer un lugar común o mera demagogia, encuentra su respaldo en los datos entregados por la encuesta CADEM (cadem,2020)

\section{Cuadro No. 2}

Presupuesto familiar

Pensando en el presupuesto familiar ¿Usted diría que mensualmente...?\%

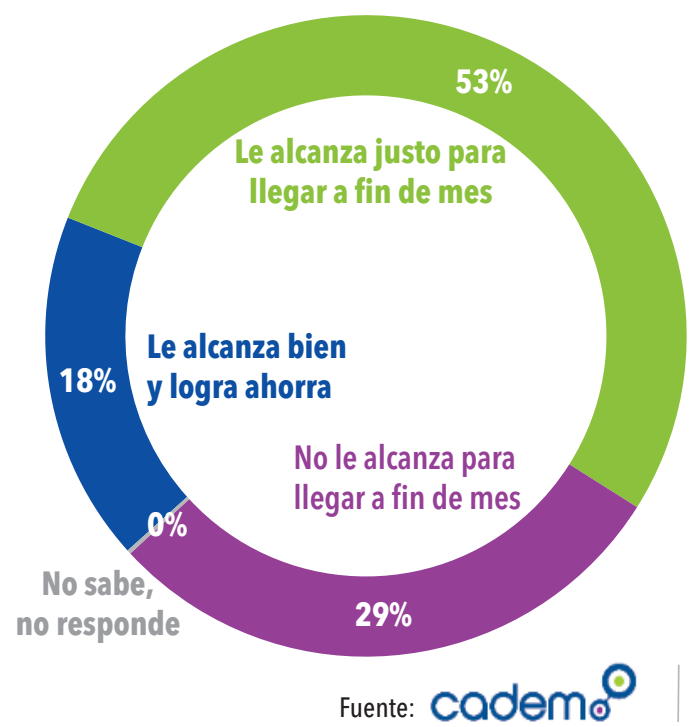


Si nos basamos, ahora, en la encuesta MORI/ FIEL sobre la economía y tópicos afines, podemos constatar que el 69\% de los chilenos miran el futuro con preocupación y el 53\% estima que el país está estancado (Mori, 2020). La verdad sea dicha, el modelo económico actual genera deudas, pero no genera empleos; la percepción de los chilenos no podría ser más pesimista: el 90\% se declara insatisfecho con la economía y el 93\% califica la distribución del ingreso nacional como injusta. Una cuestión que nos parece crucial respecto del ítem económico es que el $62 \%$ de los encuestados cree que el estallido social es consecuencia de la crisis económica (Véase Cuadro $N^{o} 3$ ).

\section{Cuadro No. 3}

¿Cree usted que la crisis económica del país es producto del estallido social o cree usted que el estallido social es consecuencia de la crisis económica?

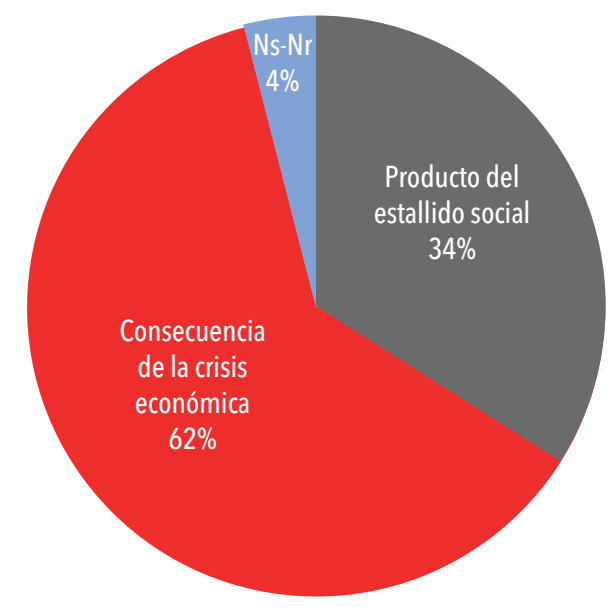

$P_{¿}$ Cree usted que la crisis económica del país es producto del estallido social o cree usted que el estallido social es consecuencia de la crisis económica?

Fuente: ${ }_{\text {BBARÓMETR@ }}$
Entre las cuestiones económicas que preocupan a los chilenos se destaca, junto a la salud y la educación, entre los primeros lugares, el tema de las pensiones. Como se sabe, en Chile se instaló un sistema privado de capitalización a cargo de entidades privadas llamadas Asociaciones de Fondos de Pensiones (AFP).

\section{(Véase Cuadro $\mathrm{N}^{\circ} 4$ )}

Estas AFP fueron creadas durante la dictadura militar por uno de los hermanos del actual presidente de Chile. A la luz de los datos entregados por las encuestas, en la actualidad, estas entidades han perdido casi totalmente la confianza de los chilenos

\section{(Véase Cuadro $N^{o} 5$ )}

De lo examinado hasta ahora, podemos colegir que el tema económico es uno de los fundamentos del estallido social que se vive en Chile. Lejos de ser el "oasis" imaginado por el primer mandatario, la sociedad chilena se nos aparece como un espacio lleno de tensiones derivadas de la precariedad salarial y un sistema privado de pensiones que es incapaz de entregar una jubilación digna a miles de chilenos de la tercera edad. Todo ello ha engendrado una desconfianza de la población hacia el actual "modelo económico chileno" inspirado en el neoliberalismo, recordemos que el 90\% de los encuestados se declara insatisfecho (Mori, 2020). En resumen, habría que insistir en aquella frase: el estallido social encuentra uno de sus fundamentos en el hecho brutal de que una gran mayoría de familias chilenas no alcanza a llegar a fin de mes. 


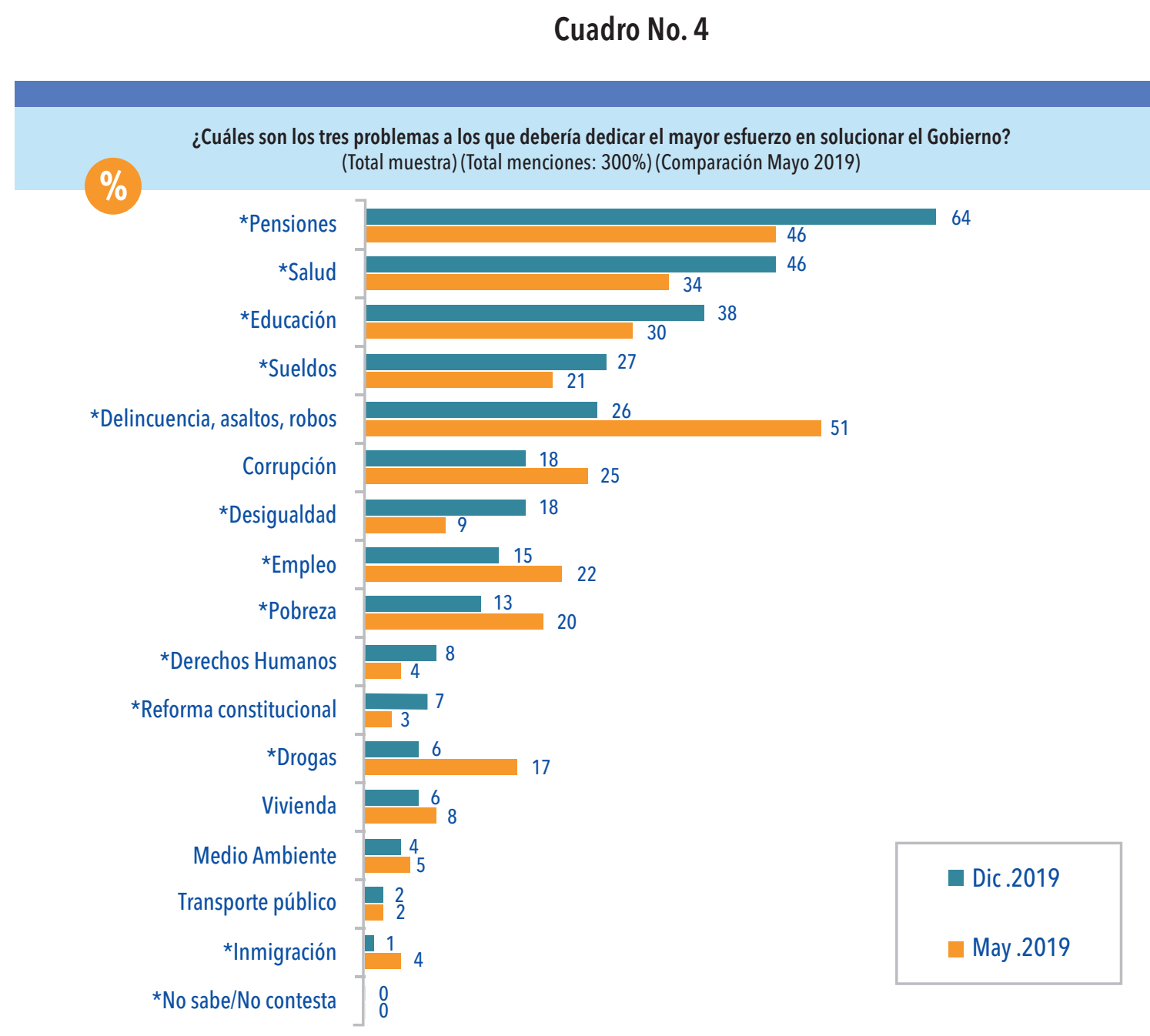

*Diferencia significativa desde un punto de vista estadístico entre las mediciones de mayo y diciembre 2019.

Fuente: CEP. ENCUESTAS NACIONALES

\section{El orden político:}

4.1. Debilitamiento de la autoridad del Estado. El estallido social en Chile ha puesto de manifiesto una pérdida de autoridad del estado, lo cual se deduce con nitidez de la misma encuesta MORI / FIEL: "La pérdida de autoridad del estado es tan profunda que hay niveles altos de aprobación a protestas ilegales: cortar el tránsito, $48 \%$; hacer barricadas, $33 \%$; atacar a carabineros, $16 \%$..." (Mori, 2020) Para expresarlo en términos sociológicos, siguiendo la tradición de Durkheim, la sociedad chilena se encuentra sumida en una profunda anomia, lo que significa que las normas sociales básicas se han degradado y que la autoridad del estado se encuentra claramente debilitada

(Véase Cuadro No 6). 


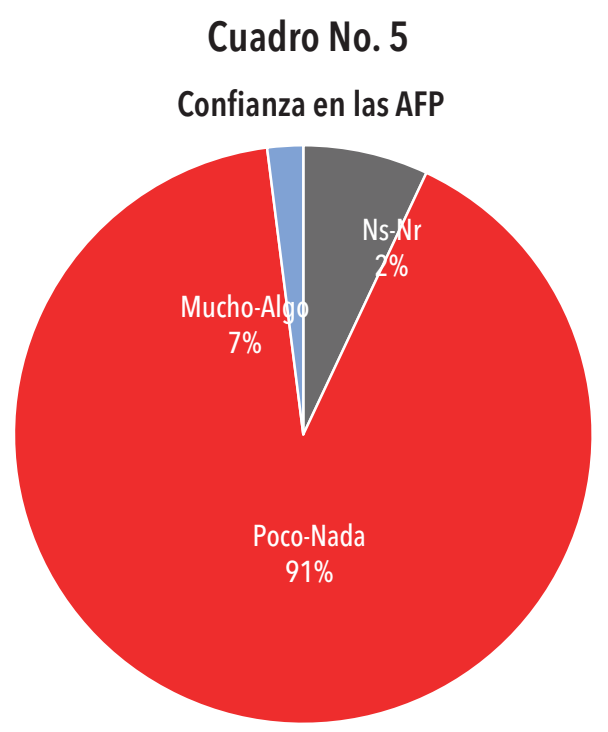

P Por favor, mire esta tarjeta y dígame, para cada uno de los grupos, instituciones o personas de la lista

¿Cuánta confianza tiene usted en que ellas operan para mejorar nuestra calidad de vida: mucha (1), algo (2), poca (3) o ninguna (4) confianza en...?

\section{Fuente: BARÓMETR@}

4.2. Desconfianza de las instituciones y partidos. Junto a un declive en la autoridad del Estado, constatamos una profunda desconfianza e las instituciones de la democracia chilena. Esta desconfianza afecta por igual al Congreso de la República, a partidos políticos, tribunales, carabineros o a la Iglesia Católica. Entre las instituciones mejor evaluadas encuentran los movimientos sociales, lo que resulta notable a la hora de comparar dicha evaluación con los partidos políticos, últimos en el listado de evaluación. Otro aspecto que debemos tener presente es la mala evaluación de los medios de comunicación chilenos que, en su mayoría, han informado de manera sesgada sobre el estallido social, exaltando los hechos de violencia, criminalizando la protesta social, ocultando las verdaderas demandas de la ciudadanía (Véase Cuadro $N^{o} 7$ ).

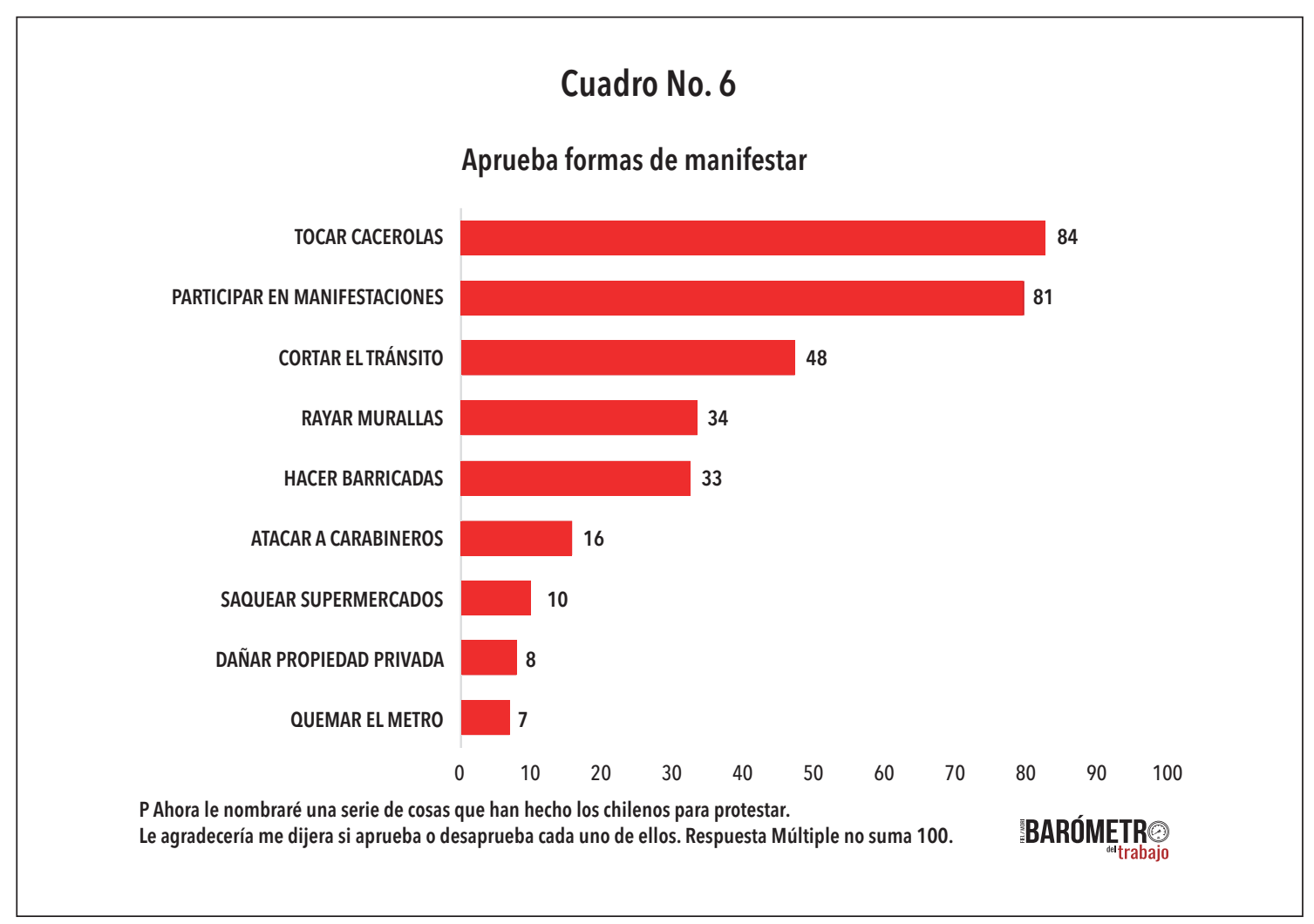

Protesta Social en Chile, 2019-2020: fracaso de un modelo económico 


\section{Cuadro No. 7}

Evaluación de instituciones y movimiento social

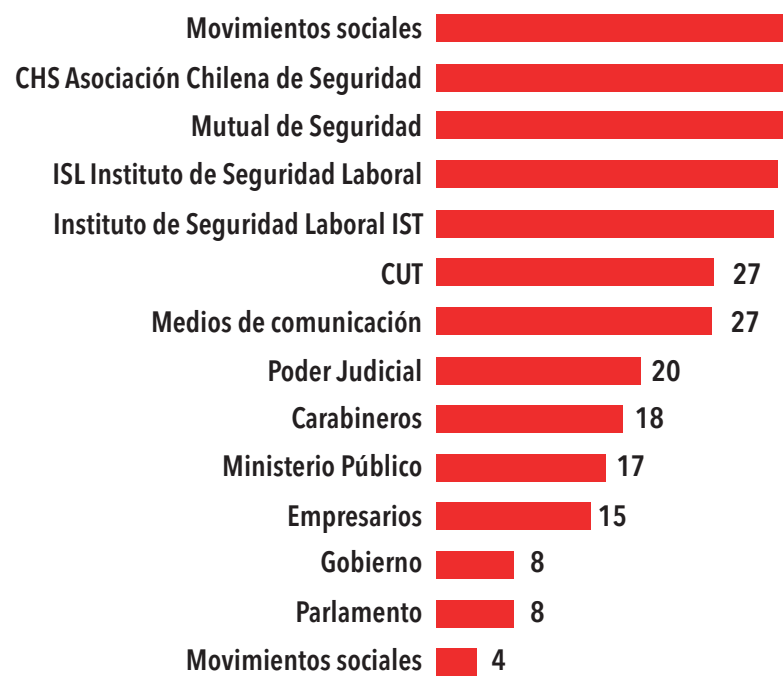

$\begin{array}{llll}0 & 20 & 40 & 60\end{array}$

80

P Ahora le pedimos que evalúe una serie de instituciones y personas, si usted cree que le hacen muy bien, bien, mal o muy mal su trabajo. Aquí: Muy Bien/Bien

Durante muchos años, tras el "retorno a la democracia”, los diversos partidos de izquierdas, centro y derechas han abandonado la función representativa de los distintos sectores sociales que reclaman para sí. La "representatividad" de antaño ha sido sustituida por la "gobernabilidad" (Cuadra,2019b). En este sentido, la "clase política" y su séquito de "intelectuales del orden" se ha tornado homogénea, convirtiéndose en los hechos en el nuevo "establishment", cómplice del poder de una derecha heredera de la dictadura.

Así, entonces, nace una "clase política" que como las pulgas de un can viven del erario nacional, usufructuando por décadas de la función pública. Las consecuencias las estamos viendo: hay un desprecio y una desconfianza profunda frente a esta "clase parásita". Incapaces de proponer ideas nuevas, han considerado "fumar opio" por cualquier cambio sustancial, conformándose, tan solo, con maquillar el obsoleto orden constitucional heredado del general Augusto Pinochet. Si los partidos políticos han fracasado, es muy probable que la ciudadanía se dé a la tarea de crear su propio espacio a través de una Asamblea Constituyente, profundizando lo que se ha dado en llamar, el "momento destituyente"

\section{(Véase Cuadro $N^{\circ} 8$ ).}




\section{Cuadro No. 8}

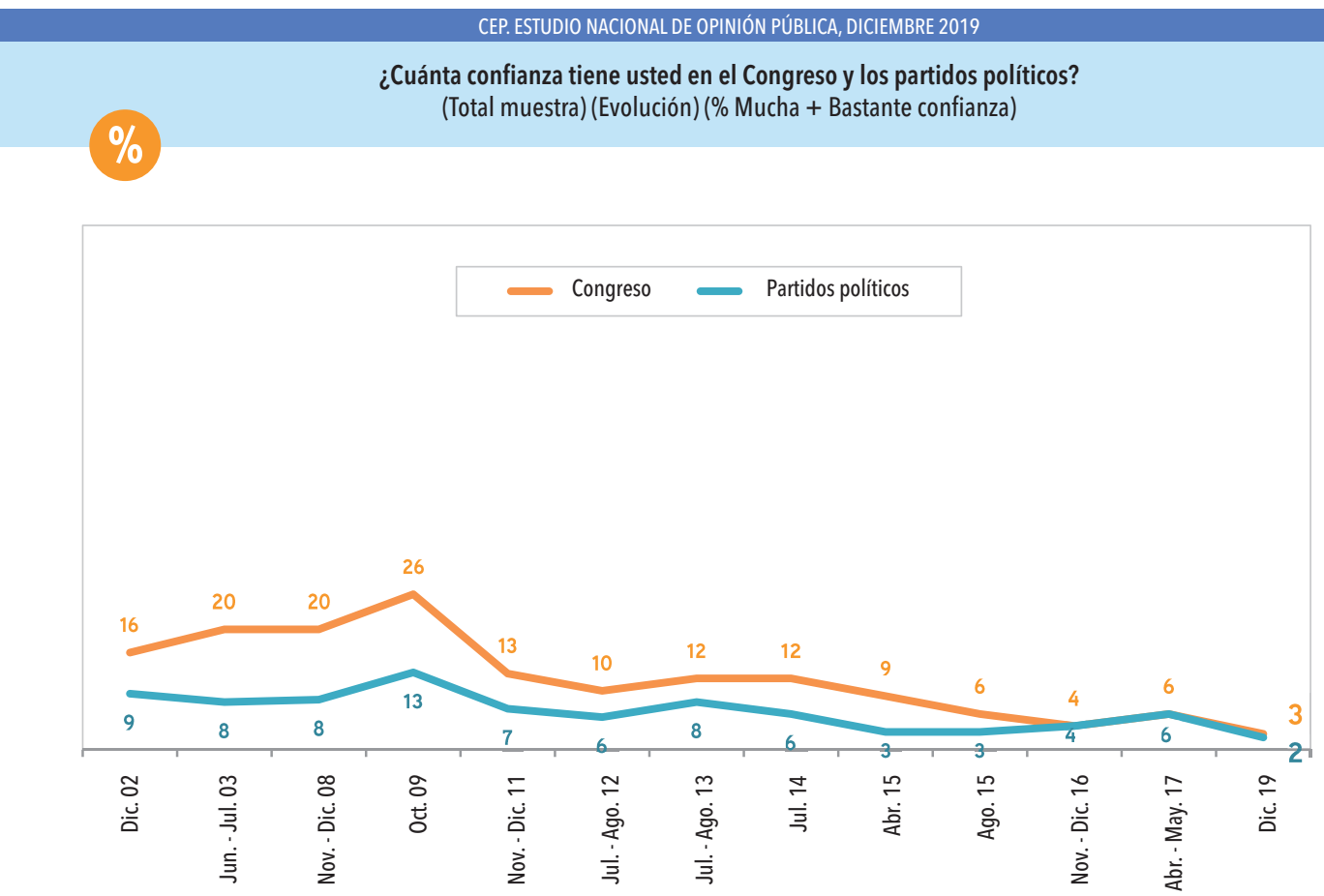

*Diferencia significativa desde un punto de vista estadístico entre las mediciones de abril-mayo y diciembre 2019. Fuente: CEP. ENCUESTAS NACIONALES

\section{5. Ámbito socio-cultural}

Las nuevas generaciones de chilenos ya no responden a las viejas claves ideológicas de otrora: irrumpe un nuevo sujeto social. Esta mutación antropológica ha generado una aguda contradicción entre un "Ethos" inédito y una "Polis" superada por la cultura y la historia. Esta contradicción fundamental se expresa como una violencia inusitada, a la cual se adhieren, cómo no, los sectores marginales de la sociedad. El fundamento último de estos nuevos comportamientos podríamos asociarlos a la llamada "Contracultura" instilada desde hace décadas entre nosotros por los grandes medios.
Recordemos que la "Contracultura" emerge después de la Segunda Guerra Mundial, caracterizada por un protagonismo de la juventud, entendida como la nueva fase culminante de la vida humana. A esto se asocia un nuevo mercado juvenil que va a orientar la cultura entera, incorporando a los mayores al "jeans" y al "rock". Por último, hagamos notar que la contracultura juvenil ha sido siempre global, diseminando por doquier su carácter iconoclasta y populista. Iconoclasta en cuanto quiere emanciparse de las viejas leyes, costumbres y ataduras morales. Populista por que la cultura juvenil va a incorporar el lenguaje y la vestimenta de los sectores marginales de la sociedad. Esta 
"Contracultura" llegó a su culmen con la llamada "Psicodelia", el tinte que tomó toda la cultura popular a nivel mundial. En la actualidad, estamos sumidos en una nueva forma de lo popular que algunos han llamado Cultura Internacional Popular, lo que nos obliga a revisar el concepto mismo de "sujeto popular".

\section{Un nuevo sujeto popular}

La llamada "sociedad de la información" se despliega junto a una "sociedad de consumidores" de alcance planetario. La comunicación y el consumo estatuyen un nuevo sujeto: el "homo digitalis" que es, al mismo tiempo, un usuario y un consumidor. Estos dos pilares constituyen, a nuestro entender, las dos cuestiones fundamentales que hacen posible y necesario replantear la pregunta por lo popular.

Si observamos la lucha y las protestas sociales de los últimos años, advertimos de inmediato que las nuevas herramientas digitales han tenido un papel importante en ellas. Esto es cierto para las protestas estudiantiles (2011) o para las actuales protestas sociales en Chile, 2019-2020. En ambas experiencias, sin embargo, no resulta claro su capacidad para constituirse en movimientos sociales con un determinado contenido político, pues, como se ha señalado:

Las olas de indignación son muy eficientes para movilizar y aglutinar la atención. Pero en virtud de su carácter fluido y de su volatilidad no son apropiadas para configurar el discurso público [...] Crecen súbitamente y se dispersan con la misma rapidez. (Han, 2014, p. 13)

Tanto en el caso de los Indignados como en el de las actuales protestas socia- les chilenas se manifiesta una difusa insatisfacción, lo que se ha dado en llamar eufemísticamente- "malestar ciudadano". Se trata de nuevas generaciones de enjambres digitales que viven arraigados a las RSO a escala mundial. Las redes sociales aparecen como el espacio político virtual que permite coordinar acciones, pero no alcanza a sedimentar un horizonte político consistente y de larga duración.

En el caso de las actuales protestas sociales en Chile se constata un debilitamiento de los partidos políticos. Las nuevas generaciones se alejan de las gramáticas rigurosas y de las organizaciones verticalistas; al igual que en un chat, las nuevas generaciones optan por la horizontalidad.

Estos nuevos sujetos sociales, insistamos, usuarios y consumidores, están redefiniendo el concepto mismo de lo popular, instalándose en las grandes urbes de nuestro continente en medio de las tensiones entre las lógicas de un poder globalizado y la cultura cotidiana que les ha tocado vivir.

Nos parece que el estallido social en Chile se inscribe, precisamente, en estas nuevas coordenadas de lo popular. Las décadas de neoliberalismo y el advenimiento de las nuevas tecnologías digitales han hecho de los sectores populares chilenos usuarios y consumidores. Son las nuevas generaciones formadas en esta nueva "clase media emergente" los que hoy protagonizan las protestas, tanto en las calles como en las Redes Sociales On line (RSO). Observemos que la información relativa a las protestas sociales en Chile se ha difundido, principalmente, por las RSO por sobre la televisión, la radio u otros medios.

(Véase Cuadro No. 9) 


\section{Cuadro No. 9}

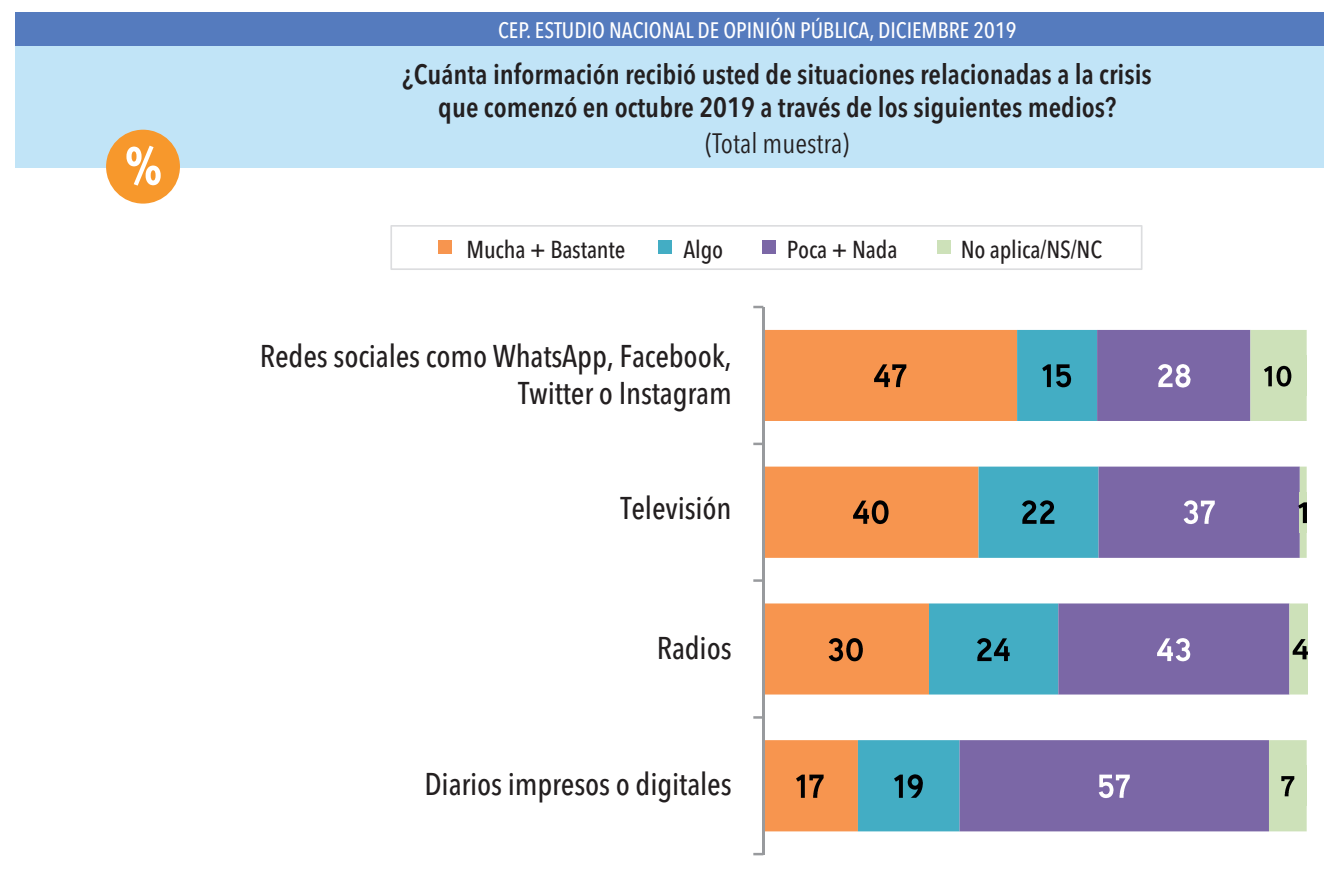

Este fenómeno que ya habíamos constatado en las protestas estudiantiles de 2011, pone de manifiesto que las nuevas generaciones han incorporado nuevos patrones de percepción, pensamiento y acción derivados del uso de las diversas redes sociales digitales. En pocas palabras, las nuevas generaciones han incorporados nuevos "habitus" que transforman sus comportamientos políticos, enfatizando en la horizontalidad y el sentido igualitario, en contraposición a la verticalidad y la burocacia propias de los partidos políticos

(Véase Cuadro $N^{o} 10$ ).

\section{Epílogo}

El balance de las protestas sociales chilenas en 2019-2020 no es muy hala- güeño. Más allá de los costos en vidas humanas, heridos graves y detenidos, los logros políticos son magros. El movimiento social, a través de sus organizaciones, ha planteado el fin de las AFP (empresas privadas de pensiones), una pensión equivalente a un salario mínimo, en fin, una salud digna sin listas de espera y un alza del sueldo mínimo. A esto se agrega una demanda por un nuevo orden político nacido de una Asamblea Constituyente capaz de abolir la vetusta constitución fraguada durante la dictadura de Pinochet que privatizó empresas estratégicas, así como las empresas sanitarias y de agua.

Nada de tales demandas ha sido satisfecha, por el contrario, el gobierno ha enfatizado su lucha contra la "violencia vandálica”. Hasta el presente, se ha presentado un proyecto de ley anti encapuchados, un proyecto de ley anti sa- 
queos, un proyecto de ley anti barricadas y un proyecto destinado a permitir a las Fuerzas Armadas resguardar la infraestructura sin necesidad de un estado de emergencia. El gobierno de Chile, como otros tantos en todo el mundo, ha convertido el "estado de excepción" en la norma.

Como se puede advertir, hay una distancia sideral entre las demandas ciudadanas y las políticas implementadas desde el gobierno. Y aunque el presidente Piñera proclame, muy optimista, que lo peor de las protestas ya ha pasado, pereciera más bien que en Chile se ha inaugurado un proceso histórico muy complejo que puede durar muchos años. En lo inmediato, no ha sido posible destituir al presidente, más allá de una simbólica acusación constitucional. Pareciera que la "clase política" ha sido capaz de apropiarse de la demanda popular por una Asamblea Constituyente y se anuncia un próximo plebiscito en abril de 2020.

Los medios de comunicación chilenos, por su parte, han logrado "criminalizar" las protestas sociales, exaltando los hechos de violencia, opacando de este modo las urgentes demandas de la ciudadanía. Después de dos meses, las organizaciones sociales son recibidas por el gobierno para escuchar sus demandas. Así, ante el desgaste natural de las protestas y su desprestigio orquestado por los poderosos medios de comunicación, el horizonte más probable es la implementación de un proceso constituyente tutelado por el Congreso, conducente a un proceso de reformas en temas como salarios y pensiones, pero sin poner en riesgo los fundamentos estructurales del sistema. El país deberá volver a los límites de su realidad: una economía neoex- tractivista de escaso desarrollo y bajo crecimiento, una democracia de muy baja intensidad y una basta cultura de consumo.

Si desde una perspectiva política nacional las protestas no han conseguido hacer realidad la mayoría de las demandas planteadas por los movimientos sociales; desde una perspectiva internacional global y regional no se puede afirmar lo mismo.

En efecto, el mayor impacto de las protestas sociales en Chile se constata en el plano internacional. Para poner en perspectiva la precaria situación en que se halla el "modelo chileno", debemos consignar ciertos factores externos que coinciden con elementos de la política interna.

Entre los factores externos, habría que señalar que el así llamado "modelo chileno" nació en un contexto de mundialización de la economía nacido en la era Reagan-Thatcher. Una tendencia que, en la actualidad, se ha revertido cuando el gobierno de Trump ha declarado que el mundo se divide hoy entre "patriotas" y "globalistas". Esto inició una verdadera "guerra comercial" de los Estados Unidos contra el eje chino-ruso y con la Unión Europea. Es evidente que este panorama internacional debilita las posibilidades de crecimiento para una economía como la chilena, pues se ha desacelerado la economía China, arrastrando con ello al mundo entero. A esto debemos agregar algunos elementos coyunturales, no menores, que lastran a la economía chilena: la competencia de economías muy dinámicas como la de Perú; la aparición de una epidemia de "Coronavirus" que ralentiza todavía más la economía China y, finalmente, una sequía mayúscula que pone en peligro la agroindustria, uno de los pilares del modelo exportador chileno. 
Todo lo anterior crea un contexto complejo y adverso a las posibilidades expansivas de la economía chilena, lo cual es un catalizador más para la creciente conflictividad social que ha puesto punto final al mito de Chile como un "oasis" latinoamericano.

Las protestas sociales en todo el país han constituido un espectáculo mediático en "Prime Time" durante varias semanas consecutivas, en las pantallas de todo el orbe; difundido, además, por la RSO, en tiempo real para todo el mundo. Resulta irónico pensar que, finalmente, la mayor desgracia de lo acontecido en Chile no la constituyen las pérdidas materiales en diversas ciudades del país sino un cierto capital simbólico. No nos engañemos, no se trata de meros incendios de estaciones y trenes del Metro, tampoco de asaltos a supermercados. Más allá de los daños materiales, lo que acaba de incinerarse es, ni más ni menos, el mito neoliberal tejido desde hace cuatro décadas y vendido al mundo como el "modelo chileno". El mito creado durante la dictadura de Pinochet se ha derrumbado en cuestión de semanas en medio de un espectáculo dantesco de cacerolazos, gritos y llamas. 


\section{Bibliografía}

Cadem (2020). Encuesta Plaza pública. Estudio No 317. Febrero 2020. www.cadem.cl

Cep (2019) Estudio Nacional de Opinión Pública. № 84. Diciembre2019. www.cepchile.cl

Cuadra, Álvaro (2018) "¿De qué estamos hablando cuando hablamos de lo popular en la era digital". En Revista Stultifera, 1 (2) 12 - 37

Cuadra, Álvaro (2019a) "Cultura de la Protesta. Protesta de la Cultura" (Cap. 10) En El Príncipe Posmoderno. Quito. Ediciones Ciespal: $79-88$

Cuadra, Álvaro (2019b) "El Príncipe posmoderno: partidos políticos y redes sociales". En Revista Chilena de Semiótica. No 11. Santiago de Chile: 8-15

Han, B.-C. (2014). En el enjambre. Barcelona: Herder.

Karmy, Rodrigo (2019) "El pueblo quiere un nuevo régimen". Opinión. En El desconcierto.

Santiago de Chile. 19 de noviembre. www.eldesconcierto.cl

Mori/Fiel (2020) Encuesta. Barómetro laboral. Enero. https://fielchile.cl/v2/estudios/

Salazar, Mauro (2019) "Destitución. Primera línea y potencia plebeya”. Opinión. El desconcierto.

Santiago de Chile. 21 de noviembre. www.eldesconcierto.cl 